\title{
Porous Silicon and Indium Doped Zinc Oxide Junctions: Synthesis, Characterization, and Application to Electroluminescent Devices
}

\author{
F. Severiano, ${ }^{1}$ G. García, ${ }^{2}$ L. Castañeda, ${ }^{3}$ and V. L. Gayou ${ }^{1}$ \\ ${ }^{1}$ Instituto Politécnico Nacional, Centro de Investigación en Biotecnología Aplicada Unidad Tlaxcala, \\ Carretera a Santa Inés Tecuexcomac, a 1.5 Km, Ex-Hacienda San Juan Molino, Ciudad de México, Mexico \\ ${ }^{2}$ CIDS-ICUAP, Benemérita Universidad Autónoma de Puebla, 14 Sur y Avenida San Claudio, Edif. 137, 72570 Puebla, PUE, Mexico \\ ${ }^{3}$ Escuela Superior de Ingeniería Mecánica y Eléctrica Unidad Ticomán, Instituto Politécnico Nacional, \\ 07340 Ciudad de México, Mexico
}

Correspondence should be addressed to F. Severiano; ohcnap007@hotmail.com

Received 11 January 2017; Revised 19 February 2017; Accepted 19 February 2017; Published 23 March 2017

Academic Editor: Shijun Liao

Copyright (C) 2017 F. Severiano et al. This is an open access article distributed under the Creative Commons Attribution License, which permits unrestricted use, distribution, and reproduction in any medium, provided the original work is properly cited.

\begin{abstract}
We report the obtaining of electroluminescent devices (ELD) from porous silicon (PS) and indium doped zinc oxide (ZnO:In) junctions. PS presented photoluminescence (PL) in the visible region of the electromagnetic spectrum. ZnO:In thin film was obtained by dip coating technique. SEM images and IR measurements showed the incorporation of the ZnO:In in the PS structure. Once obtained, the device was optically and electrically characterized. The ELD showed emission in the visible (450-850 nm) and infrared region $(900-1200 \mathrm{~nm}$ ) where it was electrically polarized. The visible emission was detected as luminescent spots on the surface. Electrical characterization was carried out by current-voltage $(I-V)$ curves. The $I-V$ curves showed rectifying behavior. It was related to the quenching of the EL with the process that takes place in the PS when it was immersed in the precursor solution of the $\mathrm{ZnO}: \mathrm{In}$.
\end{abstract}

\section{Introduction}

Since the discovery of the efficient and stable photoluminescence (PL) at room temperature of the porous silicon (PS), a large amount of investigations has been focused in obtaining electroluminescent devices (ELD) based on silicon. One of the most accepted models to explain the PL and electroluminescence (EL) in the PS is the quantum confinement effect that takes place within nanometer-sized silicon structures $[1,2]$. In the case of ELD based in PS, the origin of the electroluminescent emission has also been related to the surface/interface of luminous compounds and the amorphous structures [1]. ELD based in PS has been obtained with liquid [3] or solid state contact [4]. In this research, it was used with the second one. Different materials have been utilized as contact, for example, metals like $\mathrm{Au}$ and Ag. Due to the basic structure of luminescent devices (PS covered with a thin film used as contact), materials as
$\mathrm{Au}$ and $\mathrm{Ag}$ present the disadvantage of blocking the light emission. Besides Au nanomaterials can absorb visible light [5], reducing the electroluminescent emission. To avoid those problems the film used should be of a few nanometers (5-10) [6]. Because the contact has to be transparent to the visible emission and electrically conductive, in this work we used indium doped zinc oxide ( $\mathrm{ZnO}$ :In) as contact and transparently coated to the light emission of the PS. Zinc oxide $(\mathrm{ZnO})$ is classified as a semiconductor $\mathrm{n}$-type due to the excess of zinc [7]. $\mathrm{ZnO}$ has an attractive direct gap (3.37 eV), which can be modified to be applied to electrical and optical devices [8]. ZnO:In in this work was obtained by SOLGEL technique in the variant known as dip coating. ZnO:In obtained with this technique showed optical transmittance in the visible region of the spectrum (between 40 and 60\%) and a low resistivity (in the order of $2.05 \times 10^{-1} \Omega \mathrm{cm}$ ) [9]. Due to the characteristics in these films, they were used as contacts. Here the ELD was obtained based in PS and ZnO:In 
junctions. The devices were characterized in terms of the EL, operating variables, and the relation between the EL and PL spectra. The results of this work showed that it is possible to obtain ELD based on PS even with techniques that can damage the PS structure and also helps to understand the quenching of the electroluminescent emission in this kind of devices.

\section{Experimental Details}

Porous silicon layers (PSL) were obtained through anodic etching from crystalline silicon ( $c-S i)$ wafers p-type and ntype with resistivity of $2-4 \Omega \mathrm{cm}$ and $1-5 \Omega \mathrm{cm}$, respectively. The electrolyte used was composed of a mixture of hydrofluoric (HF) acid (40\%) and ethanol (CH3-CH2-OH) (98\%) at $1: 2$ ratio, respectively. The current density used to obtain the PSL from the p-type wafer was $6.49 \mathrm{~mA} / \mathrm{cm}^{2}$ and $40 \mathrm{~mA} / \mathrm{cm}^{2}$ in the n-type wafer (these samples were illuminated with UV light during the etching process). The etching times were 10, 20, and $30 \mathrm{~min}$ for both wafers. The deposition of transparent contact of $\mathrm{ZnO}$ :In was realized for dip coating method, using zinc acetate dehydrate, 2-methoxiethanol, monoethanolamine (MEA), and indium chloride as source solutions. Zinc acetate dehydrate was added in a mixture of 2-methoxiethanol and monoethanolamine (MEA). The molar ratio of MEA to zinc acetate was maintained at 1.0 and the final molarity of zinc acetate was chosen to be $0.6 \mathrm{M}$. The solution was stirred at room temperature for around $1 \mathrm{~h}$ to yield a homogeneous and clear solution that was aged for 7 days at room temperature in the dark, prior to deposition. The dopant source was indium chloride added in the aged solution at $[\mathrm{In}] /[\mathrm{Zn}]=3$ atomic (\%) ratio. The dip coating process was achieved when cleaned glass substrates were gradually immersed into the solution, remaining inside for $1 \mathrm{~min}$, and then mechanically extracted at a constant velocity of $1 \mathrm{~cm} / \mathrm{s}$. Then, the resulting film was dried at $200^{\circ} \mathrm{C}$ for $15 \mathrm{~min}$ in an oven to remove the solvents and organic compounds by evaporation [10]. This process was repeated 12 times in all cases. In order to diminish the corresponding resistivity, the deposited films were annealed in vacuum, oxygen, and argon atmospheres at $400^{\circ} \mathrm{C}$ for $1 \mathrm{~h}$. PL measurements were obtained using a laser with wavelength of $405 \mathrm{~nm}$ and $40 \mathrm{~mW}$ of power; the detected range was from 400 to $1100 \mathrm{~nm}$. The PSL thickness was estimated by gravimetry [11]. The sheet resistance of the $\mathrm{ZnO}$ :In films was measured with the four-point probe with the appropriate correction factors and its thickness was measured by a surface profiler Dektak IIA, having a resolution of $0.5 \mathrm{~nm}$. ZnO:In film structure was determined from $\mathrm{X}$-ray measurements in a Siemens-Kristalloflex equipment using the $\mathrm{Cu}-\mathrm{K} \alpha$ radiation $(\mathrm{K}=0.1534 \mathrm{~nm})$. For optical characterization (transmittance), the films were deposited in sodocalcic glass substrate and this was measured in a Shimadzu spectrophotometer in the ultraviolet-visible (UVVIS) range. Surface morphology studies were performed with a SEM microscope TESCAN brand vega3 SB. FTIR spectra were recorded with a spectrometer Vertex 70 (Bruker). EL spectra of the ELD were obtained with a monochromator iHR320 HORIBA brand Jobin Yvon that was coupled to
TABLE 1: Etching time and thickness of the PSL used in the ELD.

\begin{tabular}{lcc}
\hline $\begin{array}{l}\text { Etching } \\
\text { time }(\min )\end{array}$ & $\begin{array}{c}\text { p-type } \\
\text { thickness }(\mu \mathrm{m})\end{array}$ & $\begin{array}{c}\text { n-type } \\
\text { thickness }(\mu \mathrm{m})\end{array}$ \\
\hline 10 & 4 & 32 \\
20 & 13 & 96 \\
30 & 23 & 160 \\
\hline
\end{tabular}

a CCD detector model iHR320 brand Synapse. The detected range by the monochromator was from 300 to $1100 \mathrm{~nm}$. The current-voltage $(I-V)$ curves of ELD were obtained with a multimeter Keithley 2000.

\section{Results}

3.1. PS Characterization. Table 1 shows the etching time and thickness of the samples used in the elaborating of the ELD. The different thickness will help us to understand and give the description of the variables involved in the operating mechanism. The thickness of the PSL was obtained using [11]

$$
E=\frac{m_{1}-m_{2}}{\rho A_{a}},
$$

where $m_{1}$ is the mass of the c-Si wafer before the etching, $m_{2}$ is the mass of the same wafer after removing the porous layer, $\rho$ is the density of the $\mathrm{c}-\mathrm{Si}\left(\mathrm{in} \mathrm{g} / \mathrm{cm}^{3}\right)$, and $A_{a}$ is the area attacked during the etching (in $\mathrm{cm}^{2}$ ).

Figure 1 shows PL spectra obtained from the samples utilized in the ELD. As we reported in previous work [1], PS should show PL in order to achieve the electroluminescent emission. PS obtained in this work showed efficient photoluminescent emission. It can be seen in Figure 1 that the PL intensity has an increase inversely proportional to the PSL thickness. The PL decrement is the result of the oxidation process, which takes place during the etching or drying of the samples [12]. The slight shift at low wavelengths is due to the thinning of the silicon filaments in the PS $[12,13]$.

3.2. ZnO:In Characterization. Figure 2 shows XRD diffractogram of $\mathrm{ZnO}$ :In film, which is polycrystalline. The peak positions fit well with a crystal structure type hexagonal (wurtzite) according to the ASTM corresponding to $\mathrm{ZnO}$ powders. No extra phases of indium were detected, which revealed a low level (less than 2\%) of In incorporation into the $\mathrm{ZnO}$ lattice. In the diffractogram a peak related to the (002) planes was detected which is predominant regardless of the film thickness and the postannealing treatment. This result was expected, as the annealing temperature was lower than that required to cause structural changes in $\mathrm{ZnO}$ thin film. The addition of MEA was effective in the formation of $\mathrm{ZnO}$ films with a high degree of orientation along the (002) plane [14], while the effect of other stabilizers such as diethanolamine was to reduce the (002) preferential growth.

Figure 3 shows the transmittance spectra of the $\mathrm{ZnO}$ :In film deposited on sodocalcic glass substrate. The results showed that the transmittance of the film was near $45 \%$ in the visible region. The low transmittance is due to the hydroxide species remaining in the film and the number of immersions 
TABLE 2: Optical and electrical properties of the ZnO:In thin film utilized in the obtaining ELD.

\begin{tabular}{lccc}
\hline Sample & Thickness $(\mathrm{nm}) \pm 5.0 \%$ & Transmittance $(400-700 \mathrm{~nm})(\%)$ & Electrical resistivity $\times 10^{-1}(\Omega \mathrm{cm}) \pm 5.0 \%$ \\
\hline ZnO:In/SLGS & 350 & 45 & 2.05 \\
\hline
\end{tabular}
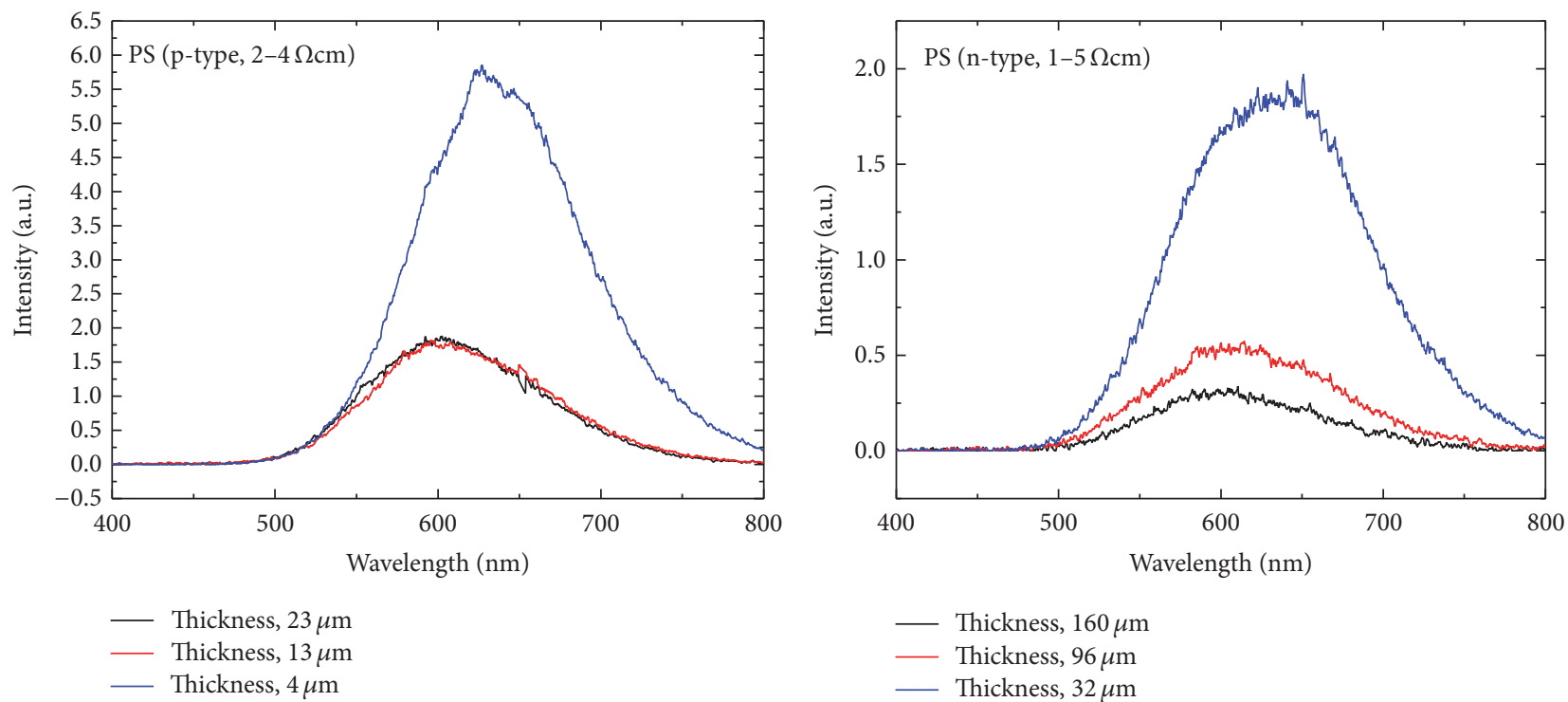

FIgURE 1: PL and thickness of the PSL utilized to get the ELD.

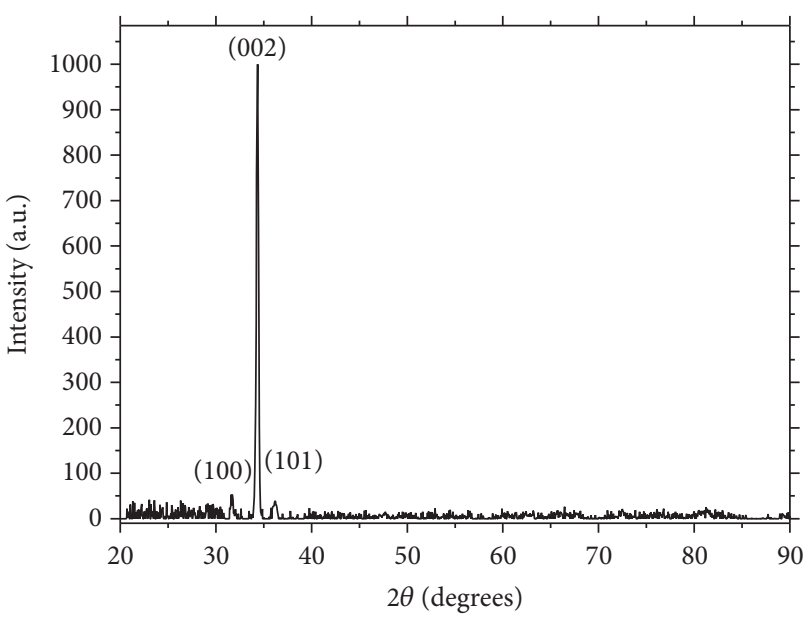

FIGURE 2: XRD diffractograms of $\mathrm{ZnO}$ :In thin film utilized as transparent and conductive coating in obtaining the ELD.

(12) in the solution to get the film. This kind of films shows good conductivity and can be used as electrical contact in the device.

Table 2 shows the electrical resistivity value and the principal characteristics for $\mathrm{ZnO}$ :In thin film deposited on sodalime glass substrate (SLGS). Electrical sheet resistance was measured by the conventional four-aligned probe method. Both optical and electrical characterization showed that the $\mathrm{ZnO}$ :In film possesses the necessary properties to be used as electrical and transparent coating to get ELD based on PSL.

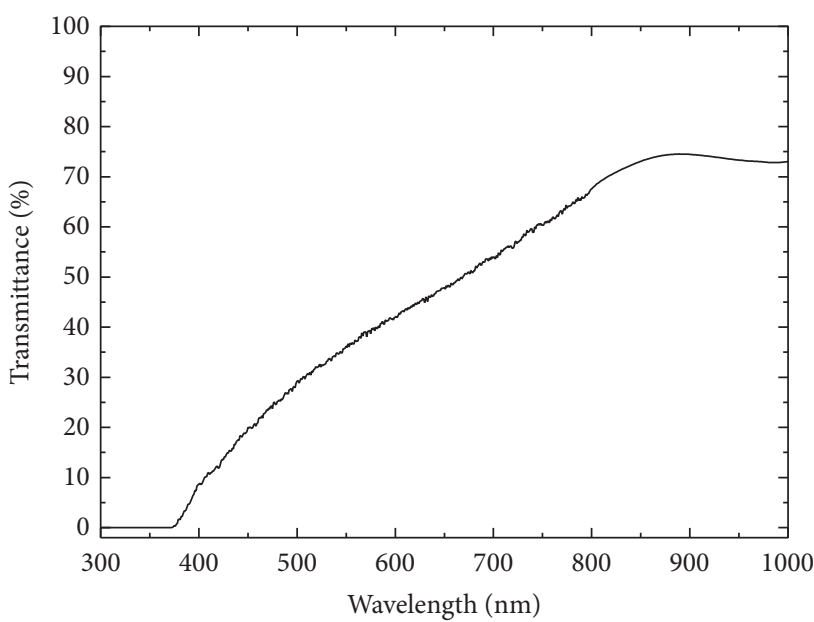

FIGURE 3: Optical transmittance spectra of $\mathrm{ZnO}$ :In thin film utilized to get the ELD.

3.3. ELD Characterization. Figure 4 shows a scheme of the ELD. Electroluminescent signals were obtained by applying variable current. The negative terminal was connected with the $\mathrm{ZnO}$ :In film (forward polarized). Light emission was observed as luminescent spots on the surface of the device. EL intensity grew with the increment of the current density. Figure 5 shows the EL spectra from the ELD. EL response depended on the device analyzed. The devices obtained with p-type wafers showed a main emission that went from 900 to $1200 \mathrm{~nm}$ (IR region). The origin of the EL emission in the 


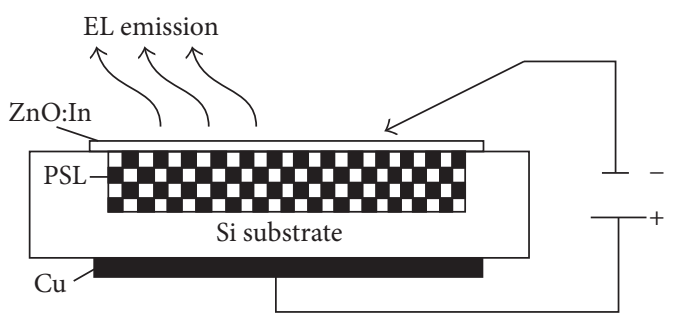

FIgURE 4: Schematic diagram of the ELD structure.

IR region can be the result of the recombinations of electronhole pairs that take place in the silicon substrate [15]. These devices also showed an emission centered at $570 \mathrm{~nm}$ which was attributed to the emitting silicon filaments that exist in the PS structure [1]. The reason that the visible emission had low intensity was because of the chemical reaction that took place when the PS was dipped in the precursor solution to get the $\mathrm{ZnO}$ :In film. The solution utilized to obtain thin films by the dip coating method had oxidryle radicals which reacted with zinc to form zinc hydroxide. Hydroxide removed part of the porous layer reducing the visible emission [16]. Once part of the porous layer was removed, the substrate (c-Si) remained exposed, and for this reason the IR emission was the main emission in these devices. The devices obtained with n-type wafers showed a signal from 450 to $850 \mathrm{~nm}$. This was due to the thickness of the porous layer, since most of it remained even after it was dipped in the precursor solution utilized in the dip coating method. This reinforces the theory that the origin of the electroluminescent emission was in the emitting silicon filaments present in the PS structure. Also, these devices showed the IR emission related to the silicon substrate.

Figure 6 shows SEM images of the surface and the profile of the samples with $32 \mu \mathrm{m}$ (n-type) and $4 \mu \mathrm{m}$ (ptype) of thickness. For the first one $(32 \mu \mathrm{m})$ the presence of square pores around $500 \mathrm{~nm}$ can be seen, and this kind of pores is characteristic in this kind of silicon substrates, Figure 6(a). The film of $\mathrm{ZnO}$ :In was over the surface of the PS and penetrated in the pores. The image corresponding to the profile, Figure 6(b), shows that $\mathrm{ZnO}$ :In was inside the pores. The images showed that the $\mathrm{ZnO}$ :In covered the internal surface of the PS, which helped the introduction of electrons in the silicon nanocrystals responsible for the electroluminescent emission. In the second sample $(4 \mu \mathrm{m})$, Figure 6(c), the corresponding image to the surface showed a granular surface and there was no evidence of pores. The image corresponding to the profile, Figure 6(d), showed a granular structure without evidence of pores too. The evidence supported the loss of the porous layer. The presence of clusters (white spots in image, Figures 6(c) and 6(d)) could be the PS that remained after the porous layer was immersed in the precursor solution to obtain the $\mathrm{ZnO}$ :In film.

Figure 7 shows the FTIR analysis carried out in the samples labeled as 4 and $32 \mu \mathrm{m}$. Absorbance peaks at 616 and $803 \mathrm{~cm}^{-1}$ and bands of 370-570, 852-1309, 1300-1500, and $1550-1700 \mathrm{~cm}^{-1}$ were perceived. Peak assignments were as follows: the peak around $616 \mathrm{~cm}^{-1}$ was from $\mathrm{SiH}$ or $\mathrm{SiH}_{2}$, deformation modes, but these peaks overlap the bulk Si-Si stretch mode at $616 \mathrm{~cm}^{-1}[17,18]$. The $803 \mathrm{~cm}^{-1}$ frequency band was associated with the growing $\mathrm{Si}-\mathrm{O}-\mathrm{Si}$ network [19]. The peak centered at $1071 \mathrm{~cm}^{-1}$ was because of dihydride species [17-19]. The breadth of this peak indicated that the dihydride species were in a heterogeneous environment. The band between 370 and $570 \mathrm{~cm}^{-1}$ could be attributed to E2 (LO) and $\mathrm{E} 1$ (LO) mode typical for $\mathrm{ZnO}$ wurtzite structure $[20,21]$. The $852-1309 \mathrm{~cm}^{-1}$ and $1550-1700 \mathrm{~cm}^{-1}$ bands can be the result of the bulk interstitial $\mathrm{Si}-\mathrm{O}-\mathrm{Si}$ asymmetric stretching mode. The broadness of this band could be due to surface oxide species [17-19]. IR spectrum from the sample of $4 \mu \mathrm{m}$ showed a peak centered at $616 \mathrm{~cm}^{-1}$, and this peak was attributed to the silicon substrate. The peak at $803 \mathrm{~cm}^{-1}$ is not present, this indicated the absence of the Si-O-Si modes, and therefore this was evidence of the absence of PS. As said before, the porous layer is removed by the precursor solution utilized to obtain the $\mathrm{ZnO}$ :In. The bands attributed to the $\mathrm{ZnO}$ were present but the intensity was very low; this could be because of the inclusion of the PS particles in $\mathrm{ZnO}$ structure, as it can be seen in the SEM analysis. On the other hand the IR spectra of the sample of $32 \mu \mathrm{m}$ showed all the peaks and bands analyzed above, which indicated the presence of the PS and the $\mathrm{ZnO}$ :In thin film. Therefore, these devices can emit light in the visible part of the electromagnetic spectrum.

Figure 8 shows the relation between the EL intensity and the current density of operation used in the ELD. For the devices obtained with p-type wafers the EL increases with the increment of the current density. These devices showed a zone for low current densities $(0-8 \mathrm{~mA})$ which did not show EL emission; this denies the direct excitation of luminescence centers by accelerated carriers as the principal excitation mechanism of the EL, suggesting that the localized electronhole pairs were responsible for the emission which was created by trapping an electron and hole from the conduction and the valence band, respectively [22]. The devices obtained with n-type wafers showed a similar behavior to the devices that were prepared with the p-type wafers. These devices showed a maximum operating current; after this, EL intensity began to decrease. The only exception was the sample with $32 \mu \mathrm{m}$ of thickness, and this device did not show EL.

The inset in Figure 8 shows the $I-V$ curves from the devices. These were typical $I-V$ curves for a $\mathrm{ZnO}: \mathrm{In} / \mathrm{PS} / \mathrm{c}-\mathrm{Si}$ structure and showed the rectifying characteristic behavior of these devices. For the case of the emission in the visible region, spots of white light merged together as the current was increased, and the light could be seen by the naked eye. In addition to the white light, small spots on the surface emitted red light, and this was revealed by a closer examination of the EL at lower potentials.

\section{Discussion}

4.1. Analysis of the Results. To understand the origin of the different bands that are present in the EL emission, a comparison between the EL and PL spectra of the PSL and the ELD was developed, Figure 9. The EL and PL intensity were normalized to carry on this study. 

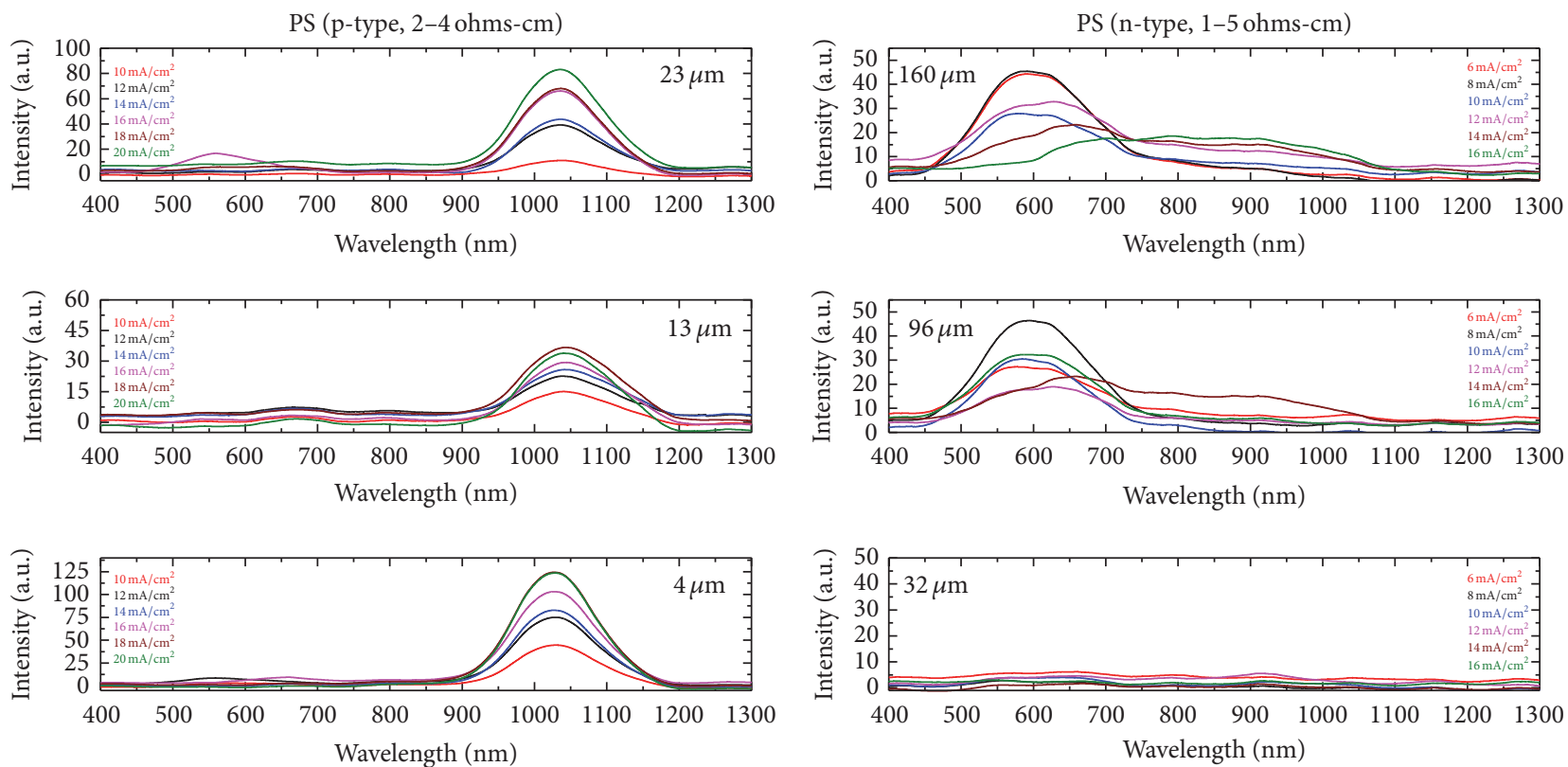

FIGURE 5: EL spectra obtained from the ELD. The image shows the response of the device with different current densities.
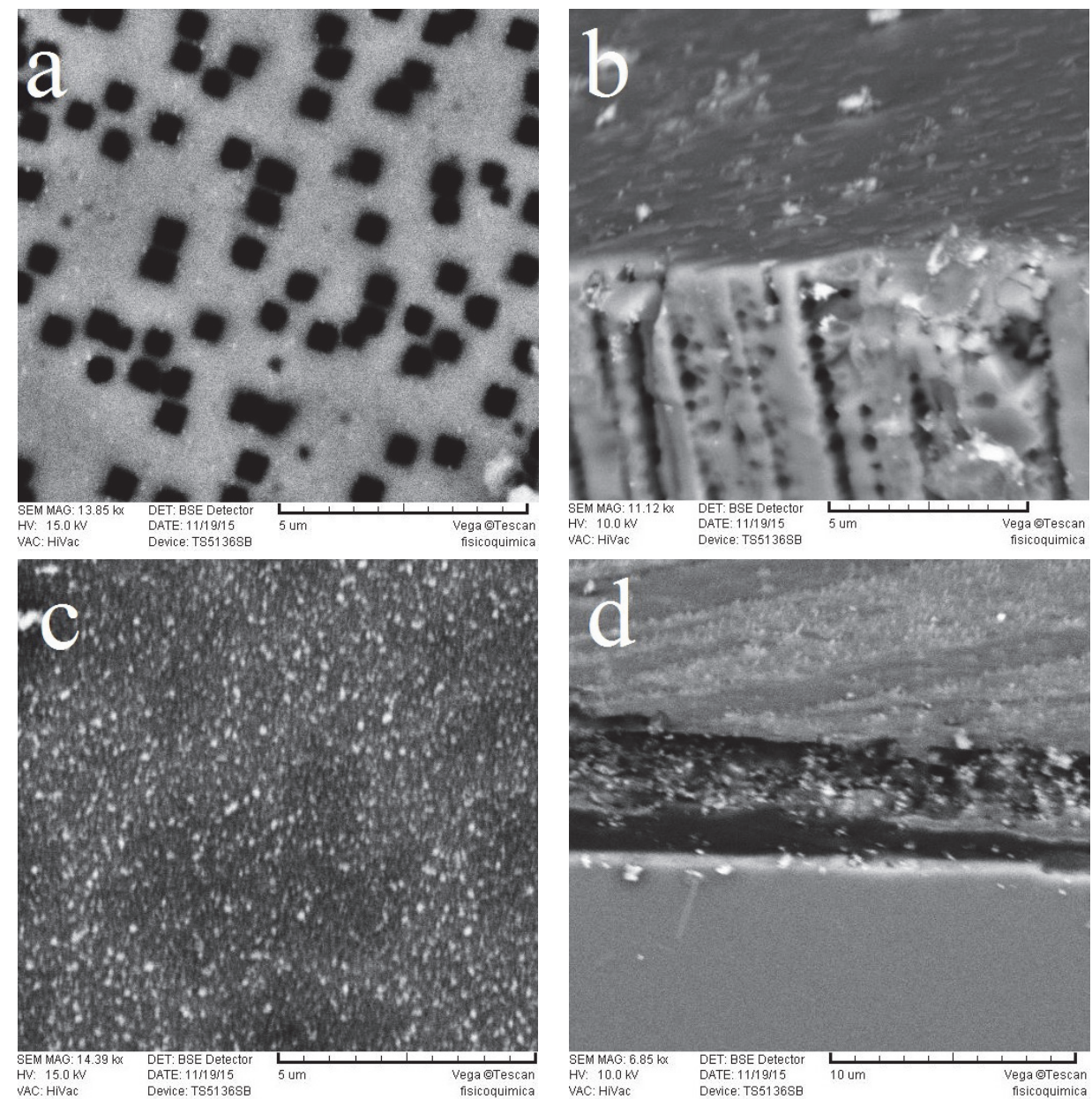

FIGURE 6: SEM images show the union between the PS and ZnO:In. 


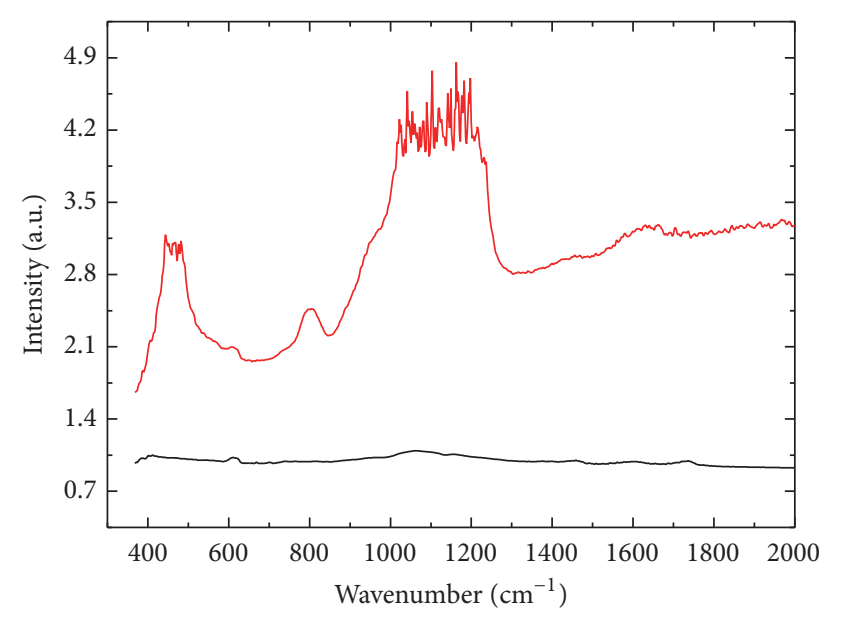

$-4 \mu \mathrm{m}$

$-32 \mu \mathrm{m}$

FIGURE 7: IR spectra from the ELD selected. The peaks and bands support the hypothesis of the loss of PS.

For the devices obtained with p-type wafers, the corresponding peak to the PL of the PS can be seen, around the $650 \mathrm{~nm}$ (black). The PL spectra (blue) of the heterostructure showed the peak attributed to the PS and the peak corresponding to the $\mathrm{ZnO}$ :In (around $500 \mathrm{~nm}$ ), the peak of the PS was lower in comparison with the $\mathrm{ZnO}$, and this was due to the attack that took place when the PS was submerged in the solution to get the $\mathrm{ZnO}$ :In film. A simple way to explain the sol-gel process is starting from the synthesis of the gel of silicate. This is achieved hydrolyzing a precursor (monomeric tetra-alkoxide) where it was used as catalyst a mineral acid $\left(\mathrm{HCl}, \mathrm{HNO}_{3}, \mathrm{H}_{2} \mathrm{SO}_{4}, \mathrm{H}_{3} \mathrm{PO}_{4}\right.$, $\mathrm{HF}$, acetic acid, etc.). The hydrolysis occurred by the attack of the oxygen from water to the core from the silicon atom according to the following reaction:

$$
\underset{\mathrm{RO} \longrightarrow}{\mathrm{RO} \longrightarrow} \mathrm{Si}-\mathrm{OR}+\mathrm{H}_{2} \mathrm{O} \longrightarrow \underset{\mathrm{RO} \longrightarrow}{\mathrm{RO} \longrightarrow} \mathrm{Ri}-\mathrm{OH}+(\mathrm{ROH})
$$

where $\mathrm{R}$ represents a compound of the alkyl group as $\mathrm{CH}_{3}$ and $\mathrm{C}_{2} \mathrm{H}_{5}$. The silicon can be replaced by $\mathrm{Zn}$, Ti, or $\mathrm{Zr}$. The existence of $\mathrm{Zn}(\mathrm{OH})_{2}$ in the precursor solution affects the porous layer, reducing the emission from PS. This was the reason that we could not see any emission in the visible region because PS was attacked by the precursor solution of the ZnO:In. Finally, when the peaks in the EL spectra were analyzed, it could be seen that the predominant emission was in the IR region, and this was due to the electrical excitation of the silicon substrate.

For the ELD obtained with n-type wafers the same behavior for the PL of PS and the PL of the ELD can be seen, but these devices showed a predominant electroluminescent emission in the visible region due to the thickness (96 and $160 \mu \mathrm{m})$ of the PSL. This was because the attack was not enough to eliminate the porous layer. The remaining emitting filaments in the film were responsible for the electroluminescent emission. The electrical characterization ( $I-V$ curves and intensity versus operation current density graphics) showed the existence of two regions; the first was for low current densities and this precedes the electroluminescent emission, and in the second the emission showed an increment with the rise of the current density. This suggests that the located electronhole pairs, which are created by trapping an electron and hole from the conduction and the valence band, respectively [6], are responsible for the visible EL. The deviation from the linear relationship at low current densities implies that there were some current components, which did not directly contribute. In other words, a significant amount of current precedes the onset of EL.

4.2. EL Source. Analyzing the EL spectra, the wafers of high resistivity ( $\mathrm{p}$-type and n-type) showed potential to apply ELD in the shown EL even when the PSL was attacked. There can be a relation between the electroluminescent emission and the amount of porous layer that remained after being submerged in the precursor solution to obtain the $\mathrm{ZnO}$ :In film. The electroluminescent intensities can be related to the amount of charge carriers in the porous layer. In light-emitting PSL, each nanocrystallite was supposed to be surrounded by a wide band gap region having a similar behavior as a quantum dot [22]. When a bias voltage is applied to this ensemble, a stronger electric field may be built up preferentially in the wide-gap regions because of their expected lower dielectric constant and higher resistivity. Then the conduction and valence-band edges of the nanocrystallites became shifted with respect to those of the corresponding neighboring ones (this band shift increases with the increase of applied voltage). Under a sufficient large bias voltage, a critical situation would appear locally: the energy position of the valence-band edge of a crystallite became comparable with that of the conduction band edge of the neighboring one. In this situation, any of the two following phenomena was expected to occur. First, hot electrons injected from the conduction band of the neighboring one were so energetic that could create electron-hole pairs by an impact process (process1). Second, electron-hole pairs can be created also by the tunneling of electrons from the valence band of a crystallite into the conduction band of the next one (process2). Progress of this process should significantly develop the number of carriers in the PSL and consequently led to a sharp increase in current density at the corresponding voltage; this is similar to the electrical breakdowns in reverse biased pn junctions. Otherwise, the electric current excited the oxygen interstitials in the $\mathrm{ZnO}$ : In film, which gave place to the blue light that can be seen in the EL spectrum. The infrared emission was attributed to the silicon substrate, which was excited when the electric current passed through the entire device, and for this reason this can be appreciated in a better way when the PSL was getting thinner, as we reported in previous work [1].

\section{Conclusions}

ELD were obtained with $\mathrm{ZnO}$ :In/PS junctions. These devices showed emission in the visible and infrared region of the electromagnetic spectrum. The devices showed emission in the 

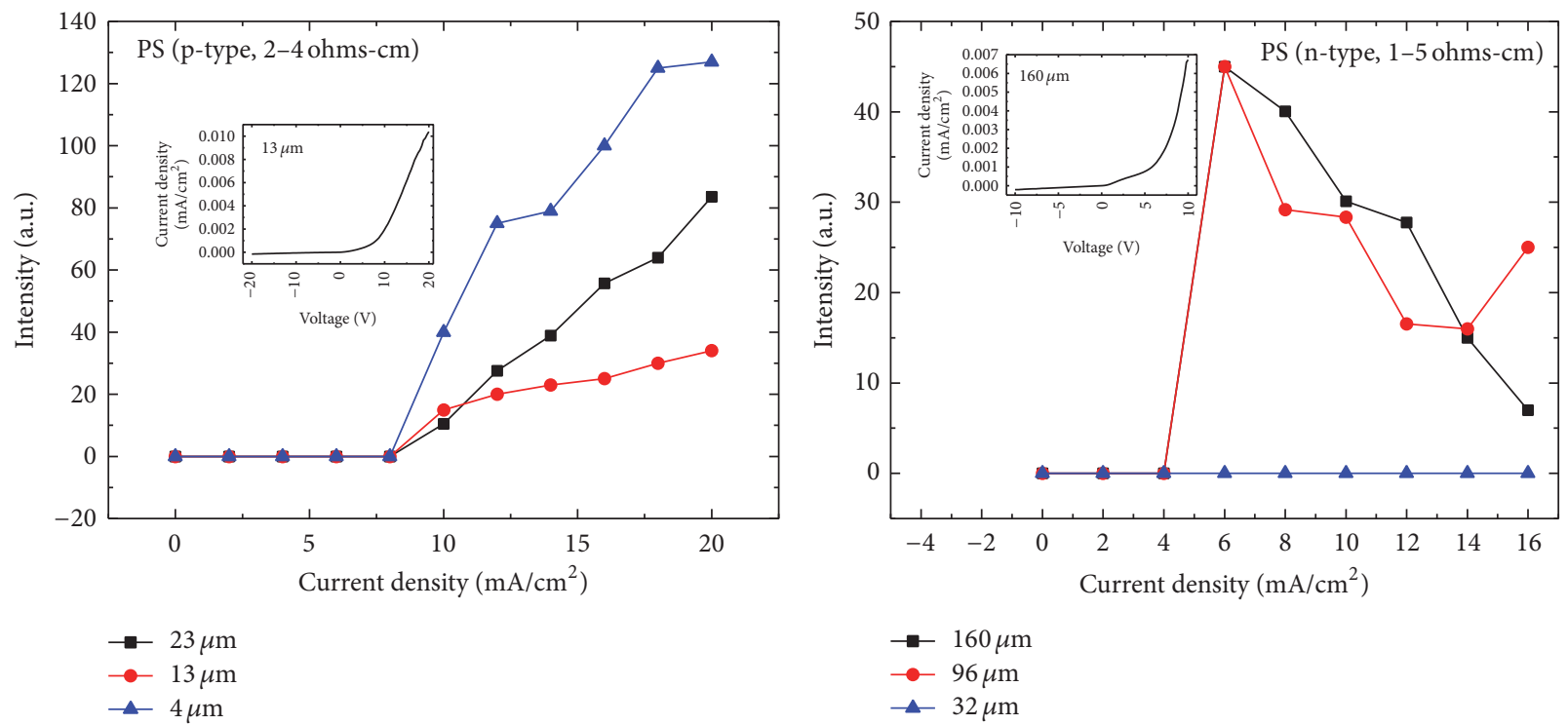

Figure 8: The graphics show the behavior of the electroluminescent intensity versus operation current density. The inset shows the $I-V$ curves acquired from the ELD.
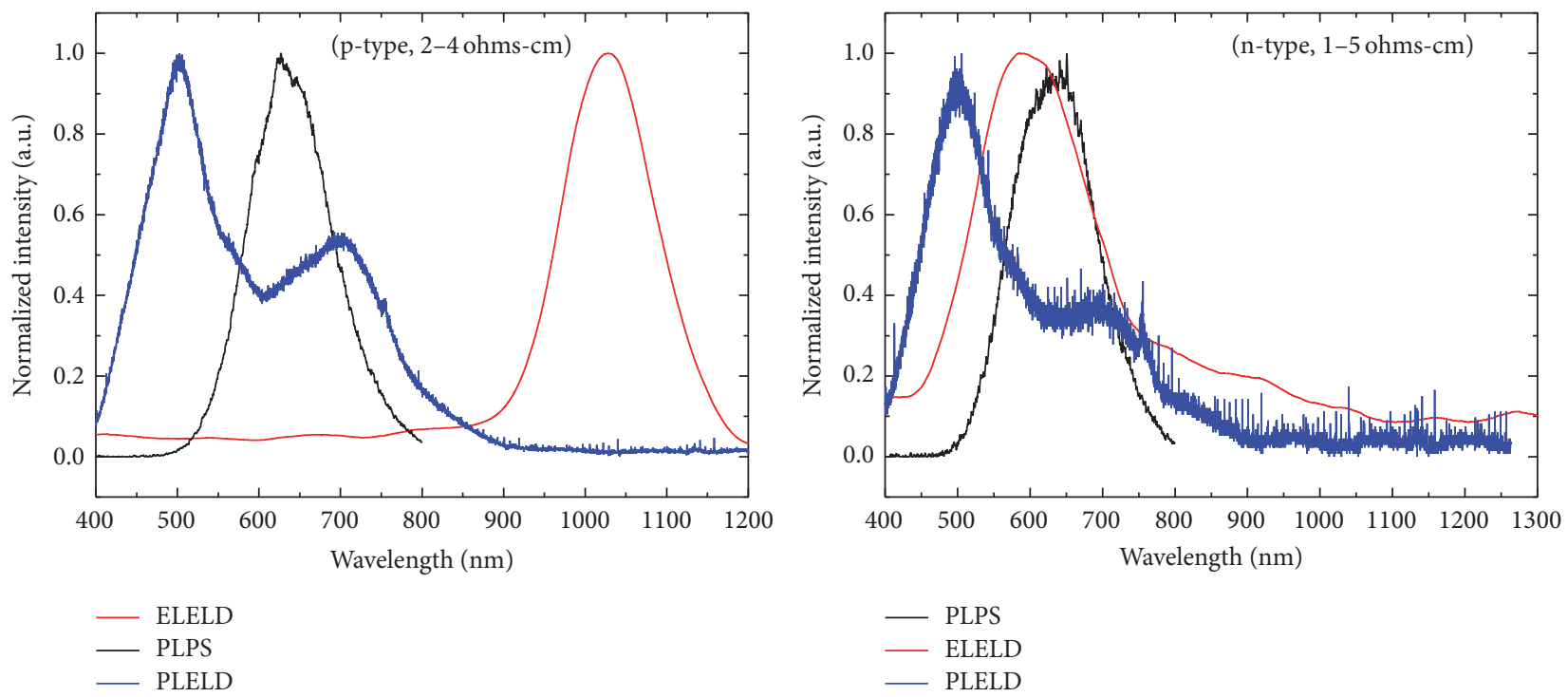

Figure 9: Comparison of PL (of the PS and ELD) and EL (of the ELD) spectra.

visible region even when the porous layer was attacked by the oxidryle radicals present in the precursor $\mathrm{ZnO}$ :In solution. This demonstrates that PS is a good material to obtain ELD. In addition, it was proved that the electroluminescent emission was integrated by the emission of $\mathrm{ZnO}$ :In, PS, and the silicon substrate.

\section{Conflicts of Interest}

The authors declare that they have no conflicts of interest.

\section{Acknowledgments}

F. Severiano thanks CONACyT for its support through 33741 studentship. The authors gratefully acknowledge the financial support from the Escuela Superior de Ingeniería Mecánica y Eléctrica Unidad Ticomán, Instituto Politécnico Nacional, through Project no. 20170897.

\section{References}

[1] F. Severiano, G. García, and L. Castañeda, "Study of the electroluminescent properties of crystalline silicon wafers in devices based on junctions of indium-doped zinc oxide and porous silicon," Materials Science in Semiconductor Processing, vol. 27, pp. 326-334, 2014.

[2] L. T. Canham, "Silicon quantum wire array fabrication by electrochemical and chemical dissolution of wafers," Applied Physics Letters, vol. 57, no. 10, pp. 1046-1048, 1990.

[3] L. T. Canham, W. Y. Leong, M. I. J. Beale, T. I. Cox, and L. Taylor, "Efficient visible electroluminescence from highly 
porous silicon under cathodic bias," Applied Physics Letters, vol. 61, no. 21, pp. 2563-2565, 1992.

[4] N. Koshida and H. Koyama, "Visible electroluminescence from porous silicon," Applied Physics Letters, vol. 60, no. 3, pp. 347349, 1992.

[5] Y. Suzuki, H. Makanae, H. Kudo, T. Miyanaga, T. Nanke, and T. Kobayashi, "Anomalous infrared and visible light absorption by spherical gold nanoparticles dispersed in a comb copolymer," Applied Physics A: Materials Science and Processing, vol. 78, no. 3, pp. 335-338, 2004.

[6] T. Oguro, H. Koyama, T. Ozaki, and N. Koshida, "Mechanism of the visible electroluminescence from metal/porous silicon/n-Si devices," Journal of Applied Physics, vol. 81, no. 3, pp. 1407-1412, 1997.

[7] T. Kamura, Y. Sekil, S. Nagakari, and H. Okushi, "Junction properties and gap states of zno thin film prepared by sol-gel process," Japanese Journal of Applied Physics, vol. 31, no. 9S, pp. 3218-3220, 1992.

[8] D. Cheng, "Anti-reflection (AR) coatings made by sol-gel processes: a review," Solar Energy Materials and Solar Cells, vol. 68, no. 3-4, pp. 313-336, 2001.

[9] J.-H. Lee and B.-O. Park, "Transparent conducting ZnO:Al, In and Sn thin films deposited by the sol-gel method," Thin Solid Films, vol. 426, no. 1-2, pp. 94-99, 2003.

[10] E. J. Luna-Arredondo, A. Maldonado, R. Asomoza, D. R. Acosta, M. A. Meléndez-Lira, and M. D. L. L. Olvera, "Indium-doped $\mathrm{ZnO}$ thin films deposited by the sol-gel technique," Thin Solid Films, vol. 490, no. 2, pp. 132-136, 2005.

[11] Z. Fekih, F. Z. Otmani, N. Ghellai, and N. E. Chabanne-Sari, "Characterization of the porous silicon layers," The Moroccan Journal of Condensed Matter, vol. 7, no. 1, pp. 35-37, 2006.

[12] H. Koyama, Y. Matsushita, and N. Koshida, "Activation of blue emission from oxidized porous silicon by annealing in water vapor," Journal of Applied Physics, vol. 83, no. 3, pp. 1776-1778, 1998.

[13] R. Herino, Porous Silicon Science and Technology, Edited by J.-C. Vial and J. Derrien, Winter School Les Houches, 1994.

[14] M. Ohyama, H. Kozuka, and T. Yoko, "Sol-gel preparation of $\mathrm{ZnO}$ films with extremely preferred orientation along (002) plane from zinc acetate solution," Thin Solid Films, vol. 306, no. 1, pp. 78-85, 1997.

[15] F. Severiano, G. García, L. Castañeda et al., "Electroluminescent devices based on junctions of silicon-rich oxide with indium doped zinc oxide thin solid films," Journal of Nanoelectronics and Optoelectronics, vol. 9, no. 1, pp. 13-20, 2014.

[16] T. E. Bell, P. T. Gennissen, D. DeMunter, and M. Kuhl, "Porous silicon as a sacrificial material," Journal of Micromechanics and Microengineering, vol. 6, no. 4, pp. 361-369, 1996.

[17] D. B. Mawhinney, J. A. Glass Jr., and J. T. Yates Jr., "FTIR study of the oxidation of porous silicon," Journal of Physical Chemistry $B$, vol. 101, no. 7, pp. 1202-1206, 1997.

[18] Y. H. Xie, W. L. Wilson, F. M. Ross et al., "Luminescence and structural study of porous silicon films," Journal of Applied Physics, vol. 71, no. 5, pp. 2403-2407, 1992.

[19] C. Tsai, K.-H. Li, J. Sarathy et al., "Thermal treatment studies of the photoluminescence intensity of porous silicon," Applied Physics Letters, vol. 59, no. 22, pp. 2814-2816, 1991.

[20] A. I. Ali, C. H. Kim, J. H. Cho, and B. G. Kim, "Growth and characterization of $\mathrm{ZnO}: \mathrm{Al}$ thin film using $\mathrm{RF}$ sputtering for transparent conducting oxide," Journal of the Korean Physical Society, vol. 49, pp. S652-S656, 2006.
[21] S. Shanmugan, P. Rajamohan, and D. Mutharasu, "Performance study on an acrylic mirror boosted solar distillation unit utilizing seawater," Desalination, vol. 230, no. 1-3, pp. 281-287, 2008.

[22] E. Fred Schubert, Light-Emitting Diodes, Cambridge University Press, 2006. 

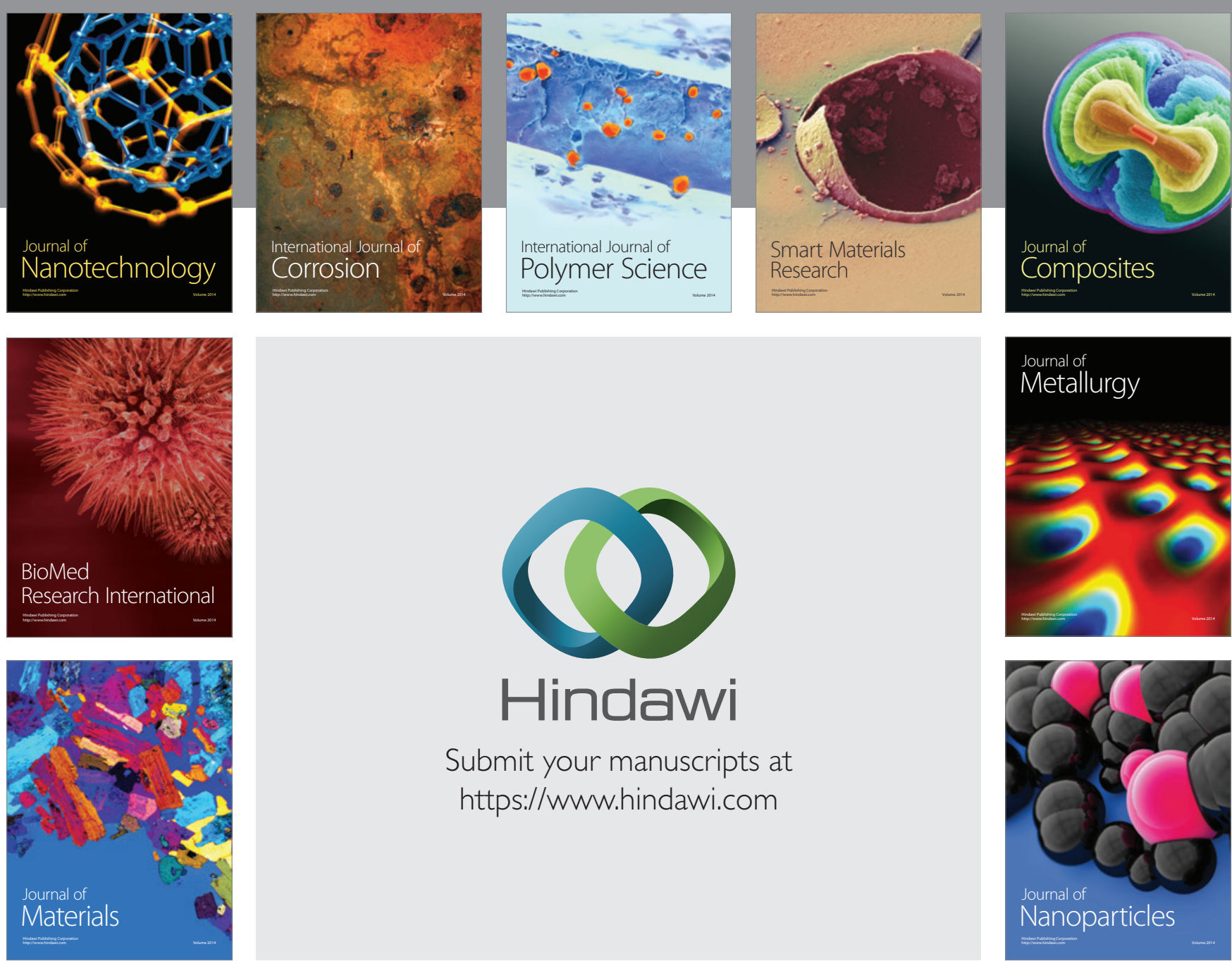

\section{Hindawi}

Submit your manuscripts at

https://www.hindawi.com

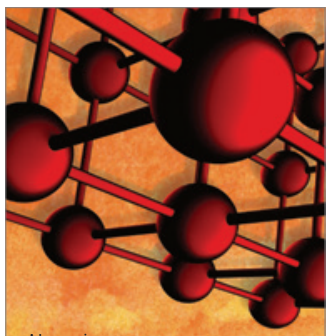

Materials Science and Engineering
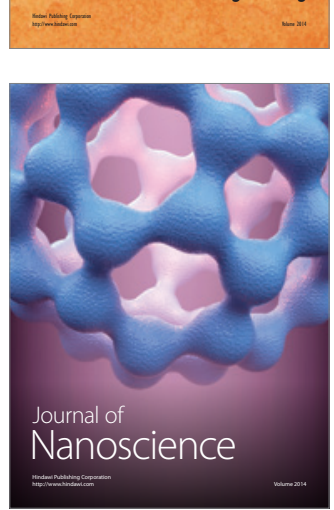
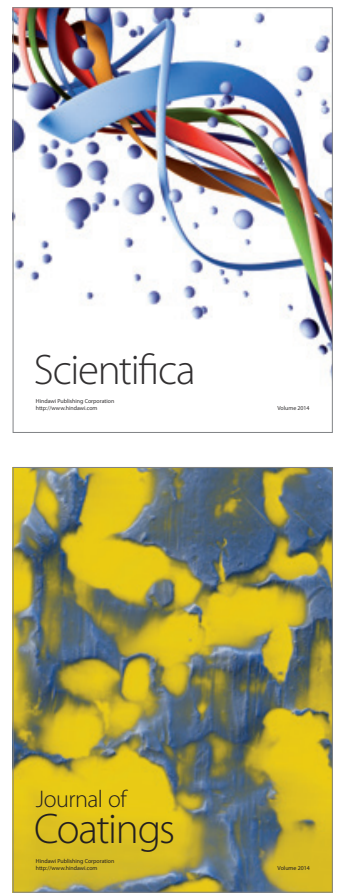
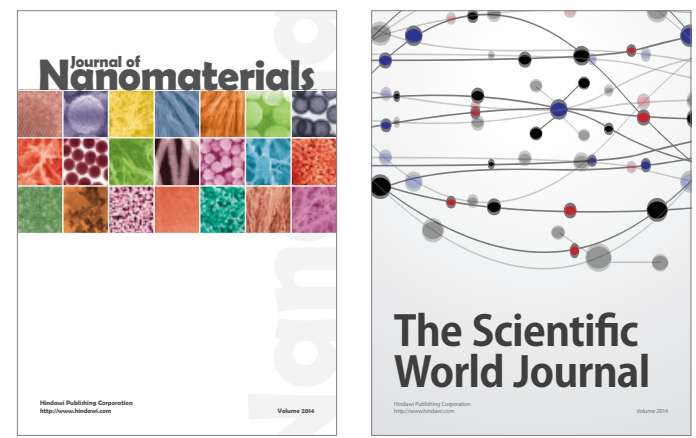

The Scientific World Journal
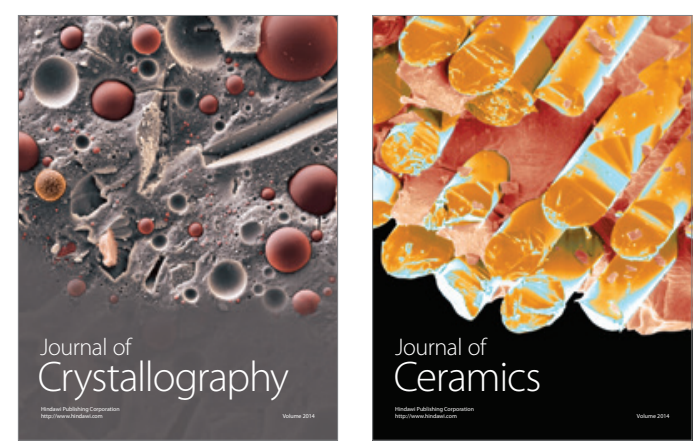
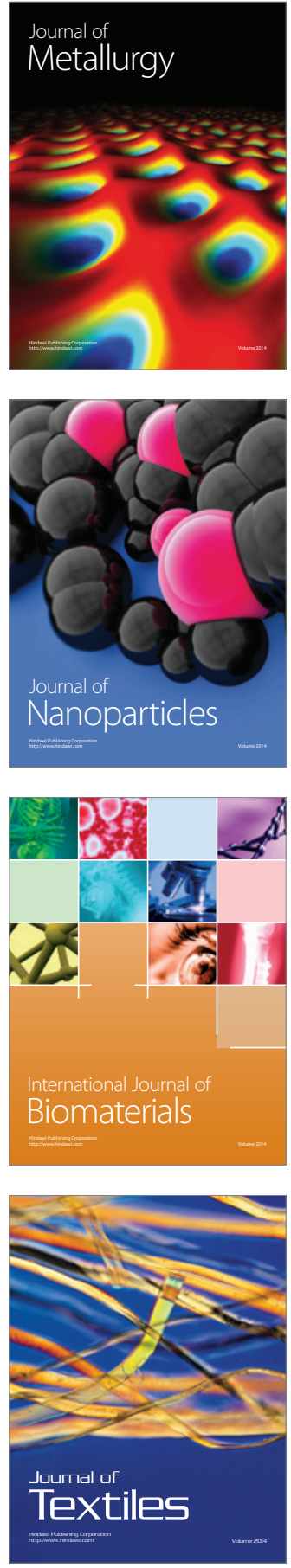